\title{
The Impact of Income Distribution on Political Knowledge of the Municipal Citizens: A Study of Ulipur Municipality of Bangladesh
}

\author{
Dr. S.M. Hasan Zakirul Islam* \\ * Associate Professor, Department of Political Studies, Shahjalal University of Science and Technology, \\ Sylhet, Bangladesh.
}

\begin{abstract}
This study focuses on the impact of income distribution on Political Knowledge of the citizens of Ulipur Municipality. Political Knowledge is one of the important components of civic orientation. Civic orientation of the people meant here their knowledge on some critical issues of public concern i.e., leadership, form of government, care taker government system and the Constitution. In this paper, it is intended to examine the impact of income distribution on such dimensions of political knowledge of the citizens of Ulipur municipality. It appears that the impact of income distribution on the knowledge of the citizens of this municipality on these basic political information is poor in some cases; it is medium in some other cases while still in other cases, it is high or very high.
\end{abstract}

Key Words: Civic orientation, political knowledge, Income Distribution, Leadership.

\section{Introduction}

Political knowledge is one of the important components of participatory activism to measure such dimension of the citizens, whether rural or urban. It is imperative to know its diverse characteristics. In this paper, it is intended to examine such dimensions and the impact of income distribution on political knowledge of the citizens of Ulipur municipality of Bangladesh.

Bangladesh is mainly a rural country. Out of 144.5 million populations, 107.8 million live in rural areas and 36.7 million people live in urban areas (Statistical Pocket Book of Bangladesh, 2008). As a first step toward local government system, the Chowkidari Panchayat was introduced in 1870 during the British rule. The act was meant mainly for rural local government. After this step, The Bengal Municipal Act, 1884 was passed during the viceroyalty of Lord Ripon for urban areas. It consolidated various previous laws on this subject. The Act was applicable to Bengal, Orissa and Assam.

The government had the powers to alter the limits of any municipality and create a new one, with a minimum population of 3000 and with an average density of 1000 people per sq mile. For the creation of a new municipality, the urban area was required to have at least three-fourths of its adult members engaged in professions other than agriculture. The number of the commissioners varied from nine to thirty in accordance with the size and population of a particular municipality. Two-thirds were to be elected and one-third to be appointed by the government (Banglapedia, 2003).

It is widely believed that the people living in municipalities/ urban areas are more conscious regarding politics and political activities than the people of the rural areas. One of the reasons may be the people of the municipalities have better opportunities to have access to the latest political information of the country due to information technologies and superhighway. Thus, people of the municipalities are well informed about political knowledge in comparison with the people of the rural areas of a country.

The urban areas, especially those areas which come under municipalities, are mostly dominated by the people migrated from the neighboring villages. Such interactive process between municipalities and villages produces an idiosyncratic blend of indigenous political culture in the localities portraying the characteristics of tradition, transition and modernity.

The rural people usually migrate to the municipalities for enjoying modern civic amenities available there. In the process of such absorption in municipal culture, the migrated rural people gradually become more conscious about politics. This condition leads them to be more participant in political activism. Municipalities are often treated as transitional areas since the culture of the migrated rural people is transformed into a quasimodern cultural trait. Thus, the political knowledge of these people, as indicated earlier, are supposed to be better than that of the rural people. 


\section{Meaning of Political Knowledge/ Information}

One element in the human capital link to political participation is political knowledge or information. It is widely understood that political knowledge is positively related to political and civic engagement: those who know more about politics are more likely to participate politically (Verba, Schlozman and Brady, 1995). Political knowledge is a political resource that can be drawn upon to reduce the costs associated with political participation: factual knowledge about political parties, for example, provides one with the ability to assess the platform that converges on one's own position on issues, allowing for more effective voting. Increased political knowledge and information has been found to lead individuals to make political judgments that are different from those they would make without the information (Delli Carpini, M. X. \& Keeter, S., 1996).

Moreover, political knowledge means some basic information on leadership, form of government, local government system, Constitution and some other public issues etc.

\section{Objectives of the Research}

In this study it is attempted to focus on Political Knowledge/ Information of the people living in municipal areas. But in this paper, it will be concentrate only on the impact of income distribution dimension. Thus the major objective of the paper here is --

* To extrapolate and analyze the causal relationship between income distribution and different aspects of political knowledge/information.

In addition, some general observations on political knowledge/ information of the municipal people based on empirical data will also be explored.

\section{Methods of Data Collection}

For our purposes here, Ulipur Municipality of Kurigram District has been selected. The selection method, though judgmental in nature, portrays the characteristics of tradition, transition and modernity of the area and also the country. This research is mainly based on primary data. So it follows mainly survey method. The instrument of data collection is an interview schedule. But other techniques like observation etc. have also been partly used whenever applicable.

\section{Sampling}

Ulipur Municipality has 09 wards consisting of 88 'Paras'. From each ward, 02 'Paras' have been randomly selected. From each 'Para' every alternative household has been selected. All the available voters aged over 18 of the research areas have been included from each selected household. Thus the total sample size stood at 525 .

\section{Description of the Research Area}

Ulipur Municipality is situated within Ulipur Upazila. It was established in 1998. Ulipur Municipality was upgraded 'B' class in 2005. This Municipality is bounded by South Pandul, North Gunaigach, Tabakpur, East Dhanranibari and West Thetrai (Banglapedia, 2003). The area of the Municipality is $27.34 \mathrm{sq} \mathrm{km}$. Ulipur Municipality is situated between $25^{\circ} 33^{\prime}$ and $25^{\circ} 49^{\prime}$ latitude and $89^{\circ} 29^{\prime}$ and $89^{\circ} 51^{\prime}$ longitude (BBS, 2009). Total population of the Municipality is 45,650 (adjusted in June, 2011); Male 22,346; Female 23,304; population density per sq $\mathrm{km} 1669$. Literacy rate is $43.04 \%$. Ulipur Municipality consists of 09 Wards, 10 Mouzas and Household 10,358 (Ulipur Municipality, Ulipur). Main occupations of the people are agriculture, agriculture labour, wage labour, commerce, service, NGOs etc.

\section{Coding}

After the collection of whole range of data, it has been processed and coded according to a code plan. Relevant concepts contained in the variable label bears a single code number. The code number ranges from 0 to 9. Example:

\begin{tabular}{lc} 
VAR NO VARIABLE NAME & VALUE LABEL \& CODE NO. \\
\hline $\begin{array}{lc}\text { Political Knowledge/Information } & \text { Medium Low }=0 \\
\text { (Naming some active political leaders of your municipality) } & \text { Medium }=1 \\
& \text { Medium High }=2 \\
\text { High }=3\end{array}$
\end{tabular}

\section{Data Management, Processing and Analysis}

After the collection of whole range of data, it has been processed and tabulated. Editing and coding of collected data has also been done simultaneously avoiding irrelevant/ unreliable information. 
The tabulated data has been analyzed according to the objectives of the research, using statistical techniques, especially marginal, cross-tabulation, chi- square test and SPSS-WIN version has been used (Statistical Package for Social Science) for data analysis in this research.

\section{Variable Specification, Operational Definition and Theoretical Framework}

Political knowledge/information is an important component of civic orientation of the people. We have used this component here as our principal dependent variable. The measures of political knowledge are the following: leadership (both local and national), Knowledge about welfare policies, form of government, local government system, constitution etc. It has been used these components in political sense of the Ulipur citizens. On the other hand, it is assumed that the indexes of Socio- Economic Resource Level (SERL) like age, income, religion, occupation, education and party status usually influence the people to mould their civic orientation. Generally these variables will be used as independent variables. But in this paper, as per our objectives we used only Income distribution as independent variable.

An analytical description of civic orientation is in order below. Civic orientation is considered as an important element of participatory behavior of the people anywhere in the world (Conover, P \& Searing, 1994). On the other hand, civic orientation generally means political knowledge as well as political interest of the people (Maloney William A. et al, 2008). It also connotes political affiliation, efficacy and tolerance while analyzing participatory behavior of the people.

When civic orientation is talked about in the context of Bangladesh, it carries the meaning as to how the people of different municipalities express their participatory behavior in the light of the above mentioned elements. The municipal people usually take lots of interest in politics. They discuss politics among themselves, hold political meetings, seminars, workshops etc and make themselves politically conscious. Civic orientation of the people also meant here to include their knowledge on some critical issues of public concern.

Generally such meaning and the above mentioned concepts have formed the base of analytical framework of this study.

\section{Sample Characteristics of Income Distribution:}

Figures 10.1 Indicate the data characteristics with percent distribution of income.

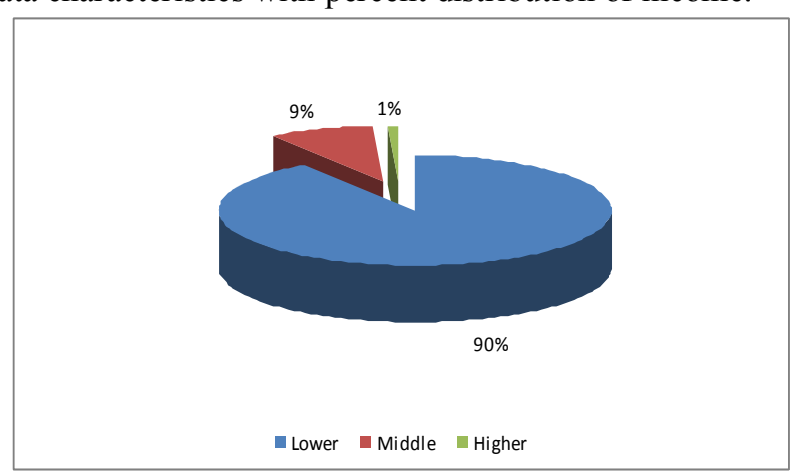

Figure-10.1 shows that monthly income of most of the respondents is very low $(90 \%)$. It is really surprising that overwhelming majority of the respondents struggle hard to maintain their respective family with their meager income. Respondents are mostly small shop owners, daily wage earners, agriculture labour, rickshaw drivers, carpenters, dish washers etc. Overall, it clearly indicates that most of the respondents of the research area are very poor portraying a real situation in the context of Bangladesh.

\section{Income Distribution and Political Knowledge: A Cross Analysis}

This paper focuses on cross-analysis between Income distribution and Political Knowledge. It is also shown $\chi^{2}$ tests of significance of these variables in Tables No: 2.1 to 2.9. It has seen that the citizens of Ulipur Municipality are knowledgeable about their respective leaders (both local and national), constitution, form of government, care-taker government system etc. But which sections of the municipal citizenry are more knowledgeable? And at what level? This section analyzes these questions.

\section{Income Distribution * Political Knowledge}

Though many cross-cultural empirical studies are available showing that richer section of the society are more conscious and thus participate more, little explanatory reasons are offered for such trend in those studies (Wolfinger, Raymond and Rosenstone Steven, 1980). In the following pages, an attempt will be made to delineate such contending dimensions of civic orientation of Ulipur Municipality based on income distribution. 
Figure-12.1

Income * Political Knowledge/Information (Naming some active political leaders of your municipality)

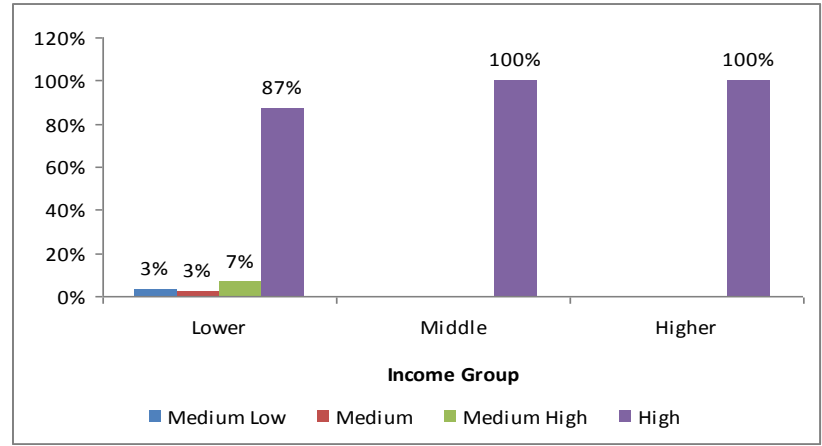

Figure 12.1 shows most of the respondents of all income groups know the names of active political leaders of their municipality. It appears that the average level of political knowledge of the citizens is very high in this respect. The Figure also indicates that citizens belonging to Middle $(11,000+)$ and higher $(25,000+)$ income groups are more conscious than other groups. It is seen from Chi-square Table-1.1 that there is no relationship between 'Income Group' and 'Naming some active political leaders of your municipality' $(\chi 2=07.131$, pvalue $=0.309$ ).

Figure-12.2 Income * Political Knowledge/Information (Hearing some active political leaders of your municipality)

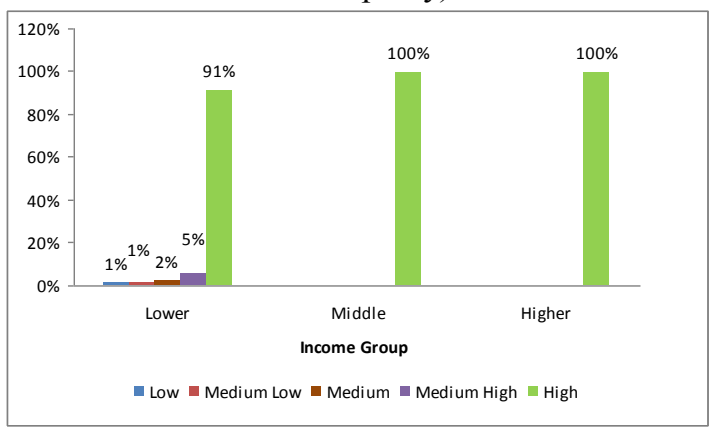

It is apparent from the Figure-12.2 that the citizens of all income groups of the respondents are well aware of their active political leaders of the municipality. If Figure is recoded as: 1= Low, 2= Medium Low, 3= Medium, 4= Medium High, 5= High, it appears that the average level of political knowledge at the level of consciousness of the citizens is very high in this respect too. But middle and higher income groups of the respondents are more conscious than the lower income groups (upto10, 000). It is quite normal in the context of Bangladesh. Most of the respondents of lower income groups are illiterate. The Chisquare Table-1.1 shows that there is no relationship between 'Income Group' and 'Hearing some active political leaders of your municipality’ $\left(\chi^{2}=04.681\right.$, $p$-value $\left.=0.791\right)$.

Figure-12.3 Income * Political Knowledge/Information (Knowing Party identification of those municipal/local leaders)

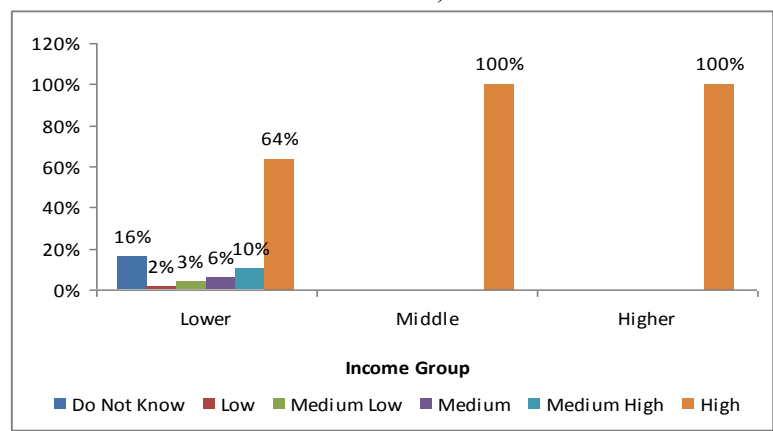

Figure-12.3 shows that vast majority of the respondents of all income groups know party identification of their municipal/local leaders. They are very conscious. It also indicates that the citizens belonging to middle and higher income groups (11,000 and above) are very conscious about their municipal/local leaders. But a good number of the respondents of the lower income groups do not know about party identification of their local 
political leaders. Most of them are housewives as it was seen before. It appears from Figure-12.3 that the average level of consciousness of the citizens is very high in this respect. There is strong relationship between 'Income Group' and 'Knowing Party identification of those municipal/local leaders' ( $\chi 2=27.161$, p-value $=0.002$, see Chi-square Table-1.1).

Figure-12.4 Income * Political Knowledge/Information (Naming some national political leaders)

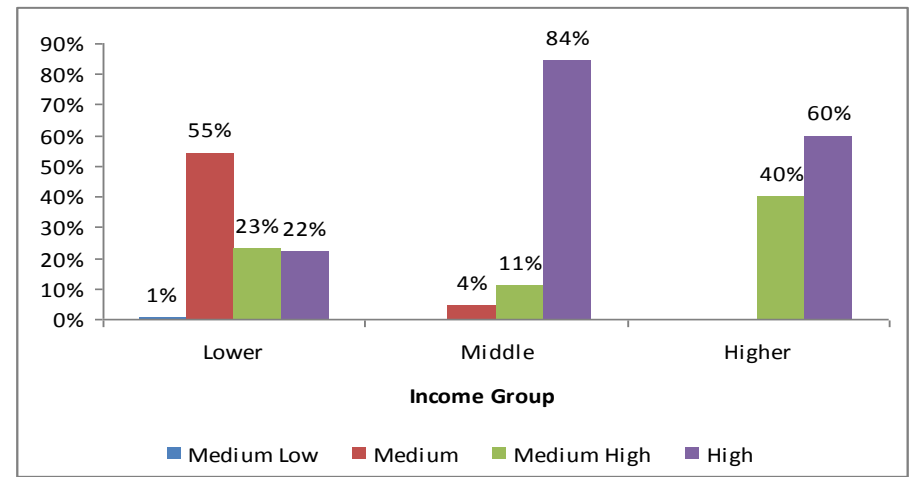

It is apparent from Figure-12.4 that the citizens belonging to all income groups can say the names of the prominent national political leaders. But most of them can say only three prominent national leaders of our country, i.e. Sheikh Hasina, Begum Khaleda Zia and Ershad. The citizens belonging to middle income groups $(11,000$ and above) are more conscious in comparison with other groups. On the other hand a significant number of the respondents stand at 'medium' or 'medium-high' levels. Interestingly the knowledge of the lower and higher income groups are much less than the middle income groups. We have indicated the probable reasons of this trend earlier. Overall, it appears from Figure-12.4 that the political knowledge of the Ulipur citizens about 'naming national political leaders', stands at medium plus level, and the pairs of variables are highly related $(\chi 2=87.990, \mathrm{p}$-value $=0.000$, see Chi-square Table-1.1).

Figure-12.5 Income * Political Knowledge/Information (Hearing about national political leaders)

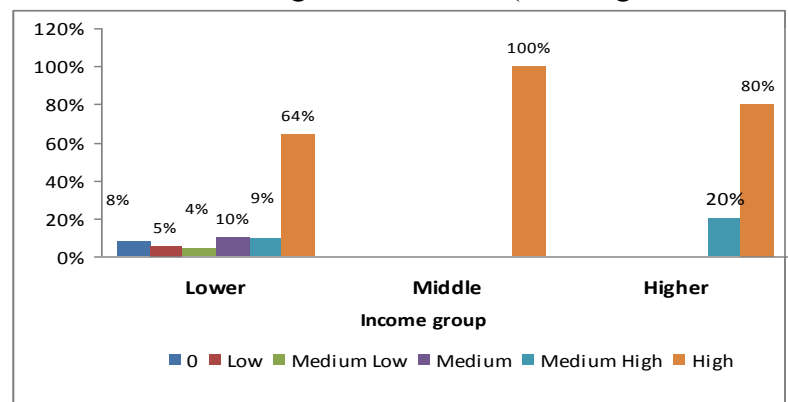

Figure-12.5 shows that citizens of all income groups of the respondents hear the names of five national leaders of Bangladesh indicating their high level of consciousness. If the Figure is recoded as: $1=$ Low, $2=$ Medium Low, 3= Medium, 4= Medium High, 5= High, it indicates that the average level of consciousness of the citizens is very high. But it also indicates other dimensions too which are also interesting. They can not themselves name those national leaders. When some names are read before them from a list, only then they can identify those national leaders. It means that they are aware of these leaders, but they can not themselves "Name" them. It indicates a sort of week mindedness in their level of consciousness. Moreover, Figure-12.5 shows that middle income group is more conscious than lower (up to 10,000) and higher (25,000 and above) income groups. It is quite normal in the context of Bangladesh. It is clear from the Chi-square Table-1.1 that there is a relationship between 'Income Group' and 'Hearing about national political leaders' $\left(\chi^{2}=25.905\right.$, $p$ value $=0.004$ ). 
The Impact of Income Distribution on Political Knowledge of the Municipal Citizens: A Study ....

Figure-12.6 Income * Political Knowledge/Information (Knowing Party identification of those national leaders)

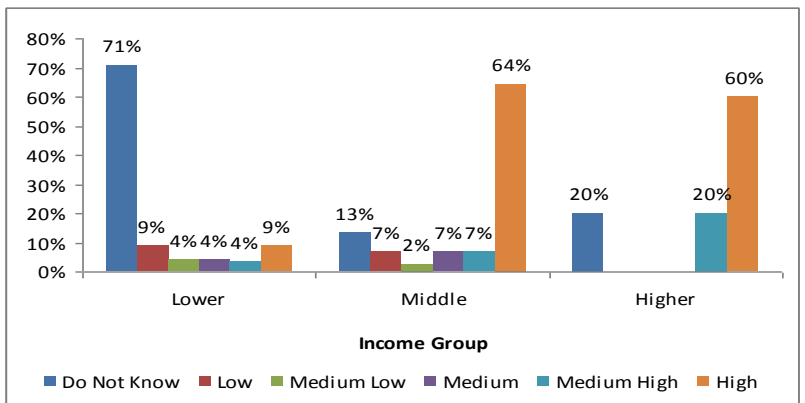

It appears from Figure-12.6 that most of the respondents of lower income groups do not know the party identification of the mentioned national leaders. While the vast majority of the middle income groups are well aware of the political affiliation of the prominent national leaders, only a few educated respondents of lower and higher income groups are well aware of party identification of the same national leaders. They are teachers, students and businessmen. Such trend can be compared to other political cultures (Verba and Nie, 1972). But it is seen that the average level of consciousness of the citizens is rather low (14\%) in this respect. Chisquare Table-1.1 show that there is significant relationship between 'Income Group' and 'Knowing Party identification of those national leaders' $\left(\chi^{2}=128.536\right.$, p-value $\left.=0.000\right)$.

Figure-12.7 Income * Knowledge about Care-taker Government System of Bangladesh Constitution

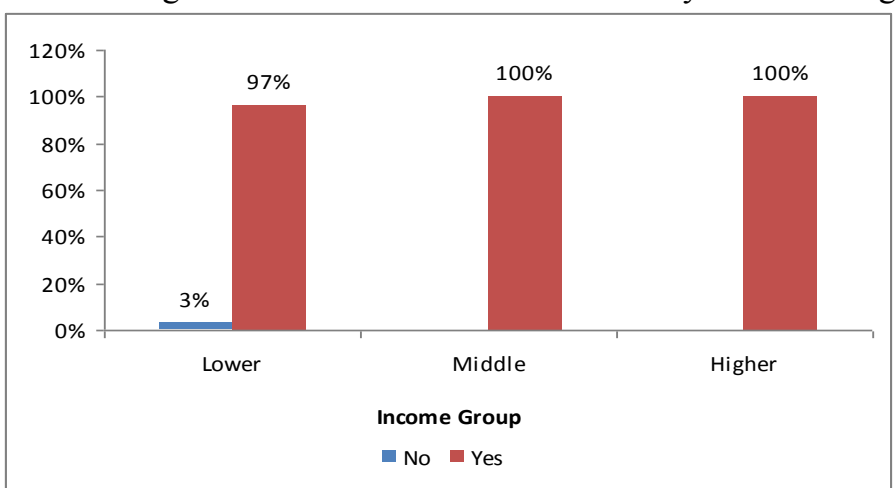

Figure-12.7 indicates that most of the respondents of all income groups are well aware of care-taker government in Bangladesh Constitution indicating their high level of consciousness. It is also an interesting trend. The citizens of the Ulipur municipality from my personal observation are well aware of only Dr. Fakruddin Ahmed's care-taker government, not the system as such (Rahman, Hasibur, 2010). Most of them are illiterate and female, as it was seen before. Only a few respondents of Ulipur municipality do not know about the care-taker government. Chi-square Table-1.1 indicate that there is no relationship between 'Income Group' and 'Knowledge about Care-taker government system of Bangladesh Constitution' $(\chi 2=01.625$, pvalue $=0.444)$

Figure-12.8 Income * Knowledge about the Form of Government in Bangladesh

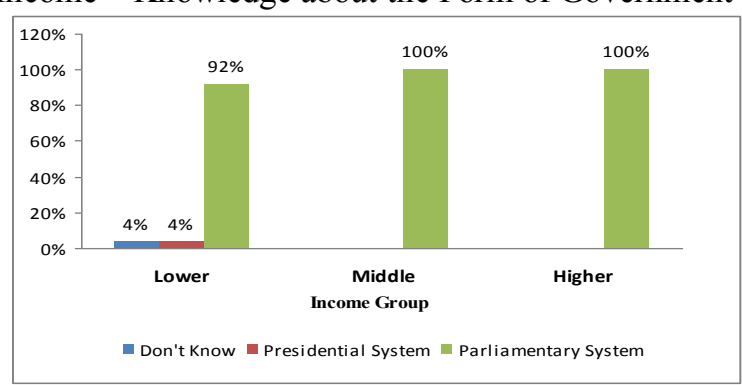

It is apparent from Figure-12.8 that the citizens of all income groups are well aware about the system of government existing in Bangladesh: parliamentary form. Few respondents who belong to 'Don't know' and 'Presidential System' categories are female, housewives and illiterate too. Figure-12.8 also shows that middle and higher income group is comparatively more conscious than lower income groups. However, from the Figure-12.8, generally it appears that the level of consciousness of the citizens is high 
in this case. But there is no relationship (see Chi-square Table-1.1) between 'Income Group' and 'Knowledge about the form of government in Bangladesh' $\left(\chi^{2}=03.947, p\right.$-value $\left.=0.413\right)$.

Figure-12.9 Income * Knowledge about the Amendments ${ }^{\dagger}$ to the Constitution

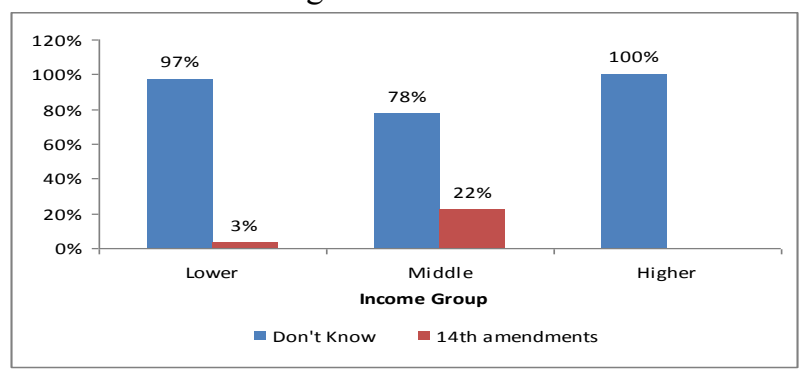

Figure-12.9 shows that most of the respondents of all income groups do not know about the amendments to the Constitution of Bangladesh. Only a few respondents are aware of the amendments to the constitution. It also indicates that the citizens belonging to 21,000-25,000 income groups are more conscious in comparison with other income groups. Most of them are also well educated as it was seen before. Another aspect is that all respondents of higher income group (25,000 and above) do not have any knowledge about the amendment to the constitution. This is very interesting. May be they are disinterested in politics. Overall, it appears from the Figure-12.9 that the knowledge of the citizens of this municipality is very low in this context. Chi-square Table-1.1 also show that there is strong significant relationship between 'Income Group' and 'Knowledge about the amendments to the constitution' $(\chi 2=35.249$, $\mathrm{p}$-value $=0.000)$.

${ }^{\dagger}$ At the time of interview, there were $14^{\text {th }}$ amendments to the constitution of Bangladesh.

\section{Summary of the Research}

From general side, it appears that most of the respondents of all income groups know the names of active political leaders of their municipality (Figure-12.1). It also indicates that the citizens belonging to middle $(11,000+)$ and higher $(25,000+)$ income groups $(100 \%$ and $100 \%)$ are more conscious than other groups. Most of the respondents of all income groups hear the names of their active local leaders (Figure-12.2). It also indicates that middle and higher income groups of the respondents are more conscious than the lower (up to 10,000) income group. On the other hand, vast majority of the respondents of all income groups know party identification of their municipal/local leaders (Figure-12.3). Overall, the respondents of all income groups are very conscious.

The citizens belonging to all income groups of the respondents can say the names of only three prominent national leaders of our country as mentioned above (Figure-12.4). It also appears that the citizens of all income groups hear the names of five national leaders of Bangladesh. It indicates their high level of consciousness (Figure-12.5). But most of the respondents of all income groups do not know the party identification of those national leaders (Figure-12.6). So the average level of consciousness of the citizens is very low in this respect.

It appears that most of the respondents of all income groups (Lower-97\%, Middle- $100 \%$ and Higher$100 \%)$ are well aware of care-taker government in Bangladesh constitution indicating their high level of consciousness (Figure-12.7).

The citizens of all income groups are well aware about the system of government existing in Bangladesh: parliamentary form. It appears that the level of consciousness of the citizens all income groups are very high in this case (Figure-12.8).

It appears that most of the respondents of all income groups (Lower-97\%, Middle-78\% and Higher$100 \%$ ) do not know about the amendments to the constitution of Bangladesh (Figure-12.9). Only few respondents are aware of the amendments to the Constitution. So their knowledge is very poor in this case.

\section{Major Findings of the Research:}

1. The citizens of this municipality of all income groups are generally knowledgeable in naming, knowing and identifying political affiliation of their active local politicians.

2. Most of the citizens of all income groups can say only the names of three prominent national leaders of the country, i.e.Sheikh Hasina, Begum Khaleda Zia and Ershad and not other national political leaders as contained in our list. The citizens belonging to all income groups of the respondents hear the names of five national leaders of Bangladesh. But most of the respondents of all income groups do not know the party identification of those national leaders. 
3. Though most of the citizens of all income group of Ulipur municipality are well aware of the system of care-taker government in Bangladesh, in reality, they are only aware of Dr. Fakruddin Ahmed's care-taker government. They are not aware the system as such.

4. In this study, most of the people of all income groups are well aware about the form of government existing in Bangladesh: parliamentary form.

5. Most of the citizens of all income groups do not know about the amendments to the constitution of Bangladesh.

\section{Conclusion}

For the above discussion, income and political knowledge are often positively correlated. Although most of the people of Bangladesh live in the rural areas, more educated and politically conscious section have been living in the urban or nearby semi-urban areas like municipality. It does not mean that rural people are not politically concerned. In fact, political programmes initiated by political parties are extended to remote rural areas from Central Unit through Upazila level Units, and Ulipur Municipality is not an exception to such trend.

Overall, it appears that the knowledge of the citizens of all income group of this municipality on some basic political information is poor in some cases; it is medium in some other cases while still in other cases, it is high or very high.

\section{Chi-Square Test Result}

Table-1.1 (Income* Other Variables)

\begin{tabular}{|c|c|c|c|}
\hline Pearson's Chi-Square Test & Value & D.F & Significance \\
\hline $\begin{array}{l}\text { Income * Political Knowledge/Information (Naming some your active } \\
\text { political leaders of Municipality) }\end{array}$ & 36.050 & 6 & 0.000 \\
\hline $\begin{array}{l}\text { Income * Political Knowledge/Information (Hearing some your active } \\
\text { political leaders of Municipality) }\end{array}$ & 37.167 & 6 & 0.000 \\
\hline $\begin{array}{l}\text { Income*Political Knowledge/Information (Knowing party identification } \\
\text { of those Municipal/local leaders) }\end{array}$ & 41.612 & 6 & 0.000 \\
\hline $\begin{array}{l}\text { Income * Political Knowledge/Information (Naming some national } \\
\text { political leaders) }\end{array}$ & 46.601 & 6 & 0.000 \\
\hline $\begin{array}{l}\text { Income * Political Knowledge/Information (Hearing about national } \\
\text { political leaders) }\end{array}$ & 7.131 & 6 & 0.309 \\
\hline $\begin{array}{l}\text { Income * Political Knowledge/Information (Knowing party } \\
\text { identification of those national leaders) }\end{array}$ & 4.681 & 8 & 0.791 \\
\hline $\begin{array}{l}\text { Income * Knowledge about Care-taker Government System of } \\
\text { Bangladesh Constitution }\end{array}$ & 27.161 & 10 & 0.002 \\
\hline Income * Knowledge about the Form of Government in Bangladesh & 87.990 & 6 & 0.000 \\
\hline $\begin{array}{l}\text { Income * Knowledge about the Amendments of Government in } \\
\text { Bangladesh }\end{array}$ & 25.905 & 10 & 0.004 \\
\hline
\end{tabular}

\section{References and notes:}

[1]. Bangladesh Bureau of Statistics, Planning Division, Ministry of Planning, Government of the People's Republic of Bangladesh. Statistical Pocket Book of Bangladesh, 2008. A new population survey throughout the country was conducted in March'2011. But the data are not yet published.

[2]. www.banglapedia.org/httpdocs/Maps. Access on May, 17, 2011.

[3]. Verba, Schlozman and Brady: Voice and Equality: Civic Voluntarism in American Politics. Cambridge: Harvard University Press, 1995

[4]. Delli Carpini, M. X. \& Keeter, S.: What Americans Know about Politics and Why It Matters?, New Haven: Yale University Press, 1996.

[5]. www.banglapedia.org/httpdocs/Maps. Access on May, 17, 2011.

[6]. The Bangladesh Bureau of Statistics, 2009.

[7]. Ulipur Municipality, Ulipur, Kurigram, Bangladesh.

[8]. Conover, P \& Searing (1994) investigate peoples' civic orientations such as their loyalties, their civic virtues, their tolerance, their political self development, and their political participation and civic behaviour. For detail, see Conover, P \& Searing, D.: "Democracy, Citizenship and the Study of Political Socialization". E Budge \& D McKey eds; Developing Democracy. London: Sage, 1994.

[9]. Maloney William A. et al (2008) analyze such meaning of Civic orientation of the citizens. See for detail, Maloney, William A. et al: “Civic Orientations: Does Associational Type Matter?". Political Studies, 2008, VOL. 56.

[10]. Wolfinger, Raymond E. and Rosenstone Steven J.: Who Votes. New Haven: The Free Press, 1980.

[11]. Verba and Nie (1972) indicate party identification in relation to electoral turnout and activity. For detail see, Verba and Nie: Participation in America: Political Democracy and Social Equality. New York: Harper and Row, 1972.

[12]. For detail, see also Rahman, Hasibur: "Governance and Election Under Military Backed Caretaker Government in Bangladesh”. Asian Studies, Savar, Dhaka: Department of Government and Politics, 2010, No.29. 